\title{
No Prior Cancer Therapy
}

National Cancer Institute

\section{Source}

National Cancer Institute. No Prior Cancer Therapy. NCI Thesaurus. Code C15903.

No prior cancer treatment. 